\title{
Reply to "Described Diagnostic Inconsistencies Were Observed with an Obsolete Version of the Xpert MTB/RIF Assay and Are Unlikely To Recur in the Current Version of the Assay"
}

\author{
Akos Somoskovi, ${ }^{\text {a,b }}$ Guido V. Bloemberg ${ }^{a}$ \\ Institut für Medizinische Mikrobiologie, Universität Zürich, Zurich, Switzerland ${ }^{\text {; }}$ Nationales Zentrum für Mykobakterien, Universität Zürich, Zurich, Switzerland ${ }^{b}$
}

W e thank Dr. Blakemore and Dr. Alland for their comments on our manuscript (1). Their letter raises important questions.

The G3 version of the Xpert MTB/RIF assay (Cepheid, Sunnyvale, CA) was available in our laboratory until the end of January 2013, with a cartridge expiration date of 7 July 2013. The case described in our paper was diagnosed in December 2012.

We are not aware of any official recall, warning, or end-user alert published and properly disseminated by the manufacturer that the G3 assay (i) is obsolete and therefore no longer reliable for routine diagnostic use with certain rifampin resistance-associated mutations, (ii) should no longer be used for routine diagnostic purposes, (iii) should be used with caution, or (iv) should be replaced by the more reliable G4 assay for known problems in the probe E region.

Dr. Blakemore and Dr. Alland refer to a press release issued in November 2011 by the Foundation for Innovative New Diagnostics (FIND) (2) as the only published evidence of G4 assay modifications. We strongly believe that press releases should be used with great caution for scientific discussions that have an impact on public health. This is in part reflected by the vague and ambiguous content of the FIND document, which summarizes the analytical performance characteristics of the G2 versus the G4 assay. Data on the G3 assay's analytical performance are not presented. For the validation of modified probe $\mathrm{E}$ of the $\mathrm{G} 4$ assay, four strains were tested by the G2 and G4 assays, but the types of mutations of the strains are not given. The document states that two of these four strains had errors with the G4 assay as well. The nature of these multiple errors is not discussed.

Although the document contained summarized information for the G2 versus the G4 assay, we have found only three short statements on the G3 assay. (i) One of the key points of the summary of findings on the $\mathrm{G} 2$ versus the $\mathrm{G} 4$ assay states the following. "High sensitivity and specificity for TB rifampin resistance detection retained. No significant differences compared to G3." (ii) A second summary statement was "Mutation detection with G4 is equivalent to G3 for multiple mutations." No further information concerning the mutation types was given. (iii) A third summary statement was "G4 easily detects Probe E mutants that are difficult to detect with the G3 version." No further information concerning the mutation types was provided.

It is unclear how these summary points were included in a document that deals with the comparison of the $\mathrm{G} 2$ assay with the G4 test without presenting results of experiments on the G3 assay itself.

In conclusion, our paper clearly highlights the importance of proper and transparent communication and, if necessary, adequate in-time discontinuation or recall of obsolete and unreliable assay versions by the manufacturer. Press releases with inadequately and ambiguously controlled and presented data cannot be seriously considered to guide routine diagnostic and patient care.

\section{ACKNOWLEDGMENT}

We have no conflicts of interest to declare.

\section{REFERENCES}

1. Somoskovi A, Deggim V, Ciardo D, Bloemberg GV. 2011. Diagnostic implications of inconsistent results obtained with the Xpert MTB/Rif assay in detection of Mycobacterium tuberculosis isolates with an rpoB mutation associated with low-level rifampin resistance. J. Clin. Microbiol. 51:9312793129. http://dx.doi.org/10.1128/JCM.01377-13.

2. Foundation for Innovative New Diagnostics. 2011. Performance of Xpert MTB/RIF version G4 assay. Foundation for Innovative New Diagnostics, Geneva, Switzerland. http://www.stoptb.org/wg/gli/assets/documents/map /findg4cartridge.pdf.

Editor: G. V. Doern

Address correspondence to Akos Somoskovi, asomoskoevi@imm.uzh.ch.

This is a response to a letter by Blakemore and Alland (doi:10.1128/JCM.02575-13).

Copyright @ 2014, American Society for Microbiology. All Rights Reserved.

doi:10.1128/JCM.02682-13 